\title{
Article \\ Photo-Responsivity Improvement of Photo-Mobile Polymers Actuators Based on a Novel LCs/Azobenzene Copolymer and ZnO Nanoparticles Network
}

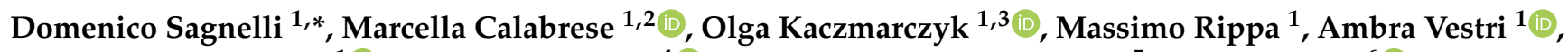 \\ Valentina Marchesano ${ }^{1}\left(\mathbb{D}\right.$, Kristoffer Kortsen ${ }^{4}\left(\mathbb{D}\right.$, Valentina Cuzzucoli Crucitti ${ }^{5}$, Fulvia Villani ${ }^{6} \mathbb{( D}$, \\ Fausta Loffredo ${ }^{6}$, Carmela Borriello ${ }^{6}$, Giuseppe Nenna ${ }^{6, * \mathbb{D}}$, Mariacristina Cocca ${ }^{7}$, Veronica Ambrogi ${ }^{2}$, \\ Katarzyna Matczyszyn ${ }^{3}{ }^{-}$, Francesco Simoni ${ }^{1}$ and Lucia Petti ${ }^{1, *}$
}

Citation: Sagnelli, D.; Calabrese, M.; Kaczmarczyk, O.; Rippa, M.; Vestri,

A.; Marchesano, V.; Kortsen, K.;

Cuzzucoli Crucitti, V.; Villani, F.;

Loffredo, F.; et al. Photo-Responsivity

Improvement of Photo-Mobile

Polymers Actuators Based on a Novel LCs/Azobenzene Copolymer and ZnO Nanoparticles Network.

Nanomaterials 2021, 11, 3320. https://

doi.org/10.3390/nano11123320

Academic Editor: Lionel Salmon

Received: 8 November 2021

Accepted: 1 December 2021

Published: 7 December 2021

Publisher's Note: MDPI stays neutral with regard to jurisdictional claims in published maps and institutional affiliations.

Copyright: (c) 2021 by the authors. Licensee MDPI, Basel, Switzerland. This article is an open access article distributed under the terms and conditions of the Creative Commons Attribution (CC BY) license (https:/ / creativecommons.org/licenses/by/ $4.0 /)$.
1 Institute of Applied Sciences and Intelligent Systems of CNR, 80072 Pozzuoli, Italy; marcellacalabrese.97@libero.it (M.C.); olga.kaczmarczyk@pwr.edu.pl (O.K.); massimo.rippa@isasi.cnr.it (M.R.); ambra.vestri@isasi.cnr.it (A.V.); valentina.marchesano@isasi.cnr.it (V.M.); f.simoni@photomat.it (F.S.)

2 Department of Chemical, Materials and Production Engineering, University of Naples Federico II, 80125 Naples, Italy; veronica.ambrogi@unina.it

3 Advanced Materials Engineering and Modelling Group, Faculty of Chemistry, Wroclaw University of Science and Technology, Wybrzeze Wyspianskiego 27, 50-370 Wroclaw, Poland; katarzyna.matczyszyn@pwr.edu.pl

4 School of Chemistry, University of Nottingham, University Park, Nottingham NG7 2RD, UK; Kristoffer.kortsen@nottingham.ac.uk

5 Department of Chemical and Environmental Engineering, University of Nottingham, University Park, Nottingham NG7 2RD, UK; valentina.cuzzucolicrucitti1@nottingham.ac.uk

6 ENEA, Italian National Agency for New Technologies, Energy and Sustainable Economic Development, Portici Research Centre, Portici, 80055 Naples, Italy; fulvia.villani@enea.it (F.V.); fausta.loffredo@enea.it (F.L.); carmela.borriello@enea.it (C.B.)

7 Institute for Polymers, Composites and Biomaterials of CNR, 80072 Pozzuoli, Italy; mariacristina.cocca@ipcb.cnr.it

* Correspondence: domenico.sagnelli@isasi.cnr.it (D.S.); Giuseppe.nenna@enea.it (G.N.); lucia.petti@isasi.cnr.it (L.P.)

Abstract: The efficiency of photomobile polymers (PMP) in the conversion of light into mechanical work plays a fundamental role in achieving cutting-edge innovation in the development of novel applications ranging from energy harvesting to sensor approaches. Because of their photochromic properties, azobenzene monomers have been shown to be an efficient material for the preparation of PMPs with appropriate photoresponsivity. Upon integration of the azobenzene molecules as moieties into a polymer, they act as an engine, allowing fast movements of up to $50 \mathrm{~Hz}$. In this work we show a promising approach for integrating $\mathrm{ZnO}$ nanoparticles into a liquid crystalline polymer network. The addition of such nanoparticles allows the trapping of incoming light, which acts as diffusive points in the polymer matrix. We characterized the achieved nanocomposite material in terms of thermomechanical and optical properties and finally demonstrated that the doped PMP was better performing that the undoped PMP film.

Keywords: actuators; photo-mobile materials; $\mathrm{ZnO}$ nanoparticles; azobenzene monomers; smart materials; liquid crystals

\section{Introduction}

Photomobile polymers (PMPs) are elastomer films that deform while irradiated with light of the proper wavelength and are controlled by modulating its intensity, polarization state and wavelength.

PMP actuators change their shape or volume when exposed to light [1] because of photo-responsive moieties [2]. Some of the most often investigated photoresponsive liquid 
crystalline elastomers and thermoset polymers are based on photochromic azobenzene molecules [3-5]. The working principle of this molecule is based on photo-induced isomerization between trans (E) and cis $(Z)$ configurations [6,7]. Such photoisomerization causes an isothermal change from an ordered phase to an isotropic phase in a liquid crystal-based matrix, which results in contraction of the material [8].

Because of their unique properties, liquid crystalline-based PMPs $[9,10]$ have been under intensive research as potential materials for actuators [5,11,12] and soft robotics [13-15] applications.

In principle, liquid crystal molecules (LCs) can exhibit an orientational order $[16,17]$. Such an order can be induced mechanically by creating grooves on the substrate where the LCs can anchor [18], or by using magnetic and electric fields. The specific LC's alignment can be preserved by performing a polymerization at the mesophase temperature, creating an ordered polymer network [5,19-22].

The responses of PMPs depend on various factors such as the LC mixture [23], crosslinker concentrations [24], orientation of the molecules [25] and light polarization [26,27]. Currently, composition improvements are going towards decreasing azobenzene moieties in the polymer because of the high costs of the relative monomers. This can be achieved by combining LCs with the azobenzene derivatives $[28,29]$. This approach provides stable monomer mesophases in a wide temperature range, better penetration of the light through the material and photoresponsivity [30].

The addition of nanoparticles (NPs) is an appealing approach to introduce distinct features to the liquid crystals. The NPs' integration influences the structure's stability [31], magnetic [32] and electro-optical [33] properties of the material, and can enhance or change the liquid crystals' own properties [34]. For example, the nanomaterials can modulate the PMP movements by increasing the temperature induced by light (the photo-thermal effect) $[35,36]$. The simultaneous use of both photochemical and photothermal effects helps to achieve reconfigurable, complex shape changes and enables the use of longer, less damaging wavelengths [29]. Interesting nanomaterials are $\mathrm{ZnO}$ nanoparticles, which are semiconductors characterized by a wide band-gap [37], emission peaks in both UV and VIS regions [38] and good heat conductivity [39]. They found diverse applications such as optoelectronics devices, photocatalysis, cosmetics and biosensing [38,40,41], and have already been used to increase the thermal conductivity [42] of the polymers, maintaining their mechanical properties at the same time. However, the major limitation is the aggregation of nanoparticles in the matrix [43] which results in phase separation [44]. Proper functionalization [45] or the choice of specific shapes and types [46] of nanomaterials seem to be the main approaches to avoid this problem [47]. In literature, it possible to find the first attempts in integrating azobenzene and $\mathrm{ZnO}$. Shah et al. (2012) found that a carboxylated azobenzene compound would self-assemble on $\mathrm{ZnO}$ nanocrystals, implementing its photochromic properties [48]. Another example would be the production of $\mathrm{ZnO}$ : azobenzene superlattice thin films fabricated from diethylzinc, water, and 4,4'-azobenzene dicarboxylic acid precursors [49]. As far as the authors' are aware, in the literature, there is not yet any report about the integration of $\mathrm{ZnO}$ nanoparticles inside an LC-based thermoset. We present a novel photomobile thermoset prepared by mixing LC-based monomers and $\mathrm{ZnO}$ nanoparticles with an average length of $100 \mathrm{~nm}$. The doped and bare PMPs were characterized to find out whether mechanical, speed and bending properties of the PMP would improve. In particular, we explored the possibility of synthesizing more efficient and mechanically-improved PMPs, also with the absence of an orientational organization of liquid crystals due to the nanoparticles. This achievement might result in remarkably efficient PMP realization, while avoiding the alignment steps.

\section{Materials and Methods}

\subsection{Materials}

LC monomers 4-Methoxybenzoic acid 4-(6-acryloyloxyhexyloxy)phenyl ester (MAPE), 4[4[6-Acryloxyhex-1-yl)oxyphenyl]carboxybenzonitrile (AOCB), 1,4-Bis-[4-(6-acryloyloxyhe 
xyloxy)benzoyloxy]-2-methylbenzene (AOBM), 4,4'-Bis[9-(acryloyloxy)nonyloxy]azobenzene (A9ZA9) were acquired at Synthon Chemicals (Wolfen,, Germany), and the photoinitiator Bis(2,4,6-trimethylbenzoyl)-phenylphosphineoxide from Sigma Aldrich (St. Louis, MO, USA). Elvamide was provided by Beamco (Supplementary Figure S2). The ZnO nanopowder was bought from Sigma Aldrich (Aldrich Cod 544906-average particle size $71 \mathrm{~nm}$-specific surface area $15 \mathrm{~m}^{2} / \mathrm{g}$ ).

\subsection{Methods}

\subsubsection{Dynamic Scanning Calorimetry (DSC)}

Differential scanning calorimetric analysis was performed using a TA-Q2000 differential scanning calorimeter (DSC, New Castel, DE, USA) equipped with an RCS-90 cooling unit (TA Instruments). The instrument was calibrated in temperature and energy with pure indium. For all measurements, approximately $3 \mathrm{mg}$ of sample in the Tzero aluminium pans was analysed at a constant nitrogen flow rate of $20 \mathrm{~mL} / \mathrm{min}$. For the evaluation of the main phase transitions, samples were heated from 0 to $200{ }^{\circ} \mathrm{C}$ at a rate of $3{ }^{\circ} \mathrm{C} / \mathrm{min}$, melted at $200{ }^{\circ} \mathrm{C}$ for $3 \mathrm{~min}$ to erase previous thermal history, then cooled to $0^{\circ} \mathrm{C}$ at $1{ }^{\circ} \mathrm{C} / \mathrm{min}$. Finally, samples were heated again at $3{ }^{\circ} \mathrm{C} / \mathrm{min}$ up to $200{ }^{\circ} \mathrm{C}$. The enthalpy of transitions was calculated by integrating the transition peaks using the software TA Universal Analysis 2000, Version 4.7A. For glass transition evaluation, all the samples were heated from $-50{ }^{\circ} \mathrm{C}$ to $150{ }^{\circ} \mathrm{C}$, held at $150{ }^{\circ} \mathrm{C}$ for $3 \mathrm{~min}$, cooled to $-50{ }^{\circ} \mathrm{C}$, and finally reheated at $150{ }^{\circ} \mathrm{C}$. The heating and cooling rates were $20^{\circ} \mathrm{C} / \mathrm{min}$. The glass transitions were calculated using the software TA Universal Analysis 2000, Version 4.7A [50].

\subsubsection{Thermal Gravimetric Analysis (TGA)}

Thermogravimetric analysis (TGA) was carried out on a Pyris 1 TGA analyzer (PerkinElmer, Waltham, MA, USA) about $5 \mathrm{mg}$ of samples were placed in an open platinum pan and heated from 30 to $800{ }^{\circ} \mathrm{C}$ at a rate of $10^{\circ} \mathrm{C} / \mathrm{min}$ using air as purge gas (flow rate: $40 \mathrm{~mL} / \mathrm{min}$ ).

\subsubsection{Order Parameter Calculation}

In order to evaluate the orientational order of the mixture of LC monomers, we estimated the order parameter using linear dichroism measurements by transmission of light through the sample with a set-up composed of: a polarized laser (wavelength 633 or $457 \mathrm{~nm}$ ), a heater chamber with an optical window (Mettler Toledo FP82HT, Columbus, OH, USA), and a power detector (Coherent Model M-2). In order to evaluate the order parameter from polarized transmitted light, we used the dichroic ratio as reported in Equation (1) when a transition moment is parallel to the principal axis of the molecules [24]:

$$
S=\frac{A_{\|}-A_{\perp}}{A_{\|}+2 A_{\perp}}
$$

where $A_{\perp}$ and $A_{\|}$are the absorbances of the cell containing the molten monomers-mix, having respectively the director $\mathbf{n}$ (defining the average direction of the molecular long axes) perpendicular or parallel to the direction of the laser polarization. The absorbance was calculated as $\log _{10}(1 / \mathrm{T})$.

The birefringence of the molten mix was investigated by setting up a polarizer before the power detector and measuring the transmission when the rubbing direction of the cell was perpendicular, parallel or tilted by 45 degrees with respect to the direction of the laser polarization. (Supplementary Figure S1).

\subsubsection{Preparation of the Cell Reactor}

For the photopolymer synthesis, cells were prepared, made of two glass slides and a plastic spacer. Each glass was dipped for $30 \mathrm{~s}$ in a solution of $1 \%$ elvamide in methanol $(w / w)$ and dried at $160{ }^{\circ} \mathrm{C}$ for $1 \mathrm{~h}$. Finally, the elvamide layers were rubbed automatically using an automatized home-made machine. The rubbed sides of the two glasses were faced towards each other in antiparallel mode (in respect to the rubbed direction) and 
spaced only by means of a $50 \mu \mathrm{m}$-thick kapton layer to get a cell reactor (Supplementary Figure S2).

\subsubsection{Synthesis of the Photo-Mobile Polymer Films}

The PMP films were prepared using a mixture of LC monomers proposed by Lahikainen et al., 2018 [51]: $53 \mathrm{~mol} \%$ of LC monomer 4-Methoxybenzoic acid 4-(6-acryloyloxyhexyloxy) phenyl es-ter (MAPE), 18 mol\% of LC monomer 4[4[6-Acryloxyhex-1-yl)oxyphenyl]carboxy benzonitrile (AOCB), 22 mol\% of di-acrylate crosslinker 1,4-Bis-[4-(6-acryloyloxyhexyloxy) benzoyloxy]-2-methylbenzene (AOBM), $6 \mathrm{~mol} \%$ of azo crosslinker 4,4'-Bis[9 -(acryloyloxy) nonyloxy]azobenzene (A9ZA9) (Synthon Chemicals), and $1 \mathrm{~mol} \%$ of photoinitiator Bis(2,4,6trimethylbenzoyl)-phenylphosphineoxide. In brief, the reaction mixture was dissolved in dichloromethane and heated up at $70{ }^{\circ} \mathrm{C}$ until all the solvent was removed. Then, the reaction mixture was left to recrystallize in the fridge overnight until it was a compact powder.

The reaction cell was heated at $100{ }^{\circ} \mathrm{C}$ and the mixture infiltrated in the reactor cell by capillarity (Supplementary Figure S2). After the infiltration, the sample was moved onto a second hotplate set at the nematic temperature $\left(50^{\circ} \mathrm{C}\right)$ and photopolymerized for $1 \mathrm{~h}$ (30 min each side) using a UV LED lamp light $\lambda=400 \mathrm{~nm}\left(12 \mathrm{~mW} / \mathrm{cm}^{2}\right)$ and then left for $24 \mathrm{~h}$ at $50{ }^{\circ} \mathrm{C}$.

This process was carried out both for bare PMPs and composites ( $\mathrm{ZnO}: 6 \% \mathrm{w} / w$ ). For the preparation of $\mathrm{ZnO}$-doped PMPs, the nanoparticles $(100 \mathrm{~nm})$ were added to the reaction mixture before the infiltration.

Undoped PMPs were labeled as Azo-LC-PMP, while ZnO-doped PMPs were labeled as Azo-LC-PMP(6\%_Z).

To understand if our procedure was reproducible, the PMPs were prepared following two different protocols. In the first, the LC mixture and the nanoparticles were dry mixed firstly with a spatula and then with a vortex to facilitate the dispersion. The second approach involved the addition of DCM to the LC $+\mathrm{ZnO}$ mixture and then letting it dry as usual. Both approaches showed the same results.

\subsubsection{UV/vis Spectral Characterization (Absorbance, Transmission, Degradation)}

Spectral characterization in UV/vis of the PMP films (Thickness $\approx 50 \mu \mathrm{m}$ ) was performed using the UV/VIS Spectrophotometer JASCO V-650 (accuracy $0.5 \mathrm{~nm}$, range 190$850 \mathrm{~nm}$, Oklahoma, OK, USA). Both total percentage transmittance T (\%) and total percentage reflectance $\mathrm{R}(\%)$ were measured using the integrating sphere JASCO ISN-722 (inside diameter $60 \mathrm{~mm}$, range 200-870 $\mathrm{nm}$ ).

The PMPs were further characterized to understand if the nanoparticles would reduce the decay time of the cis isomer of azobenzene [29]. The PMPs were irradiated for 5 and 60 min using a UVA lamp with peak wavelength at $400 \mathrm{~nm}$ with a power density of $12 \mathrm{~mW} / \mathrm{cm}^{2}$. Then, the PMPs' absorbance was measured after 1 and $24 \mathrm{~h}$. Subsequently, a background film was prepared with all the components except A9AZ9 in order to exclude the contribution of the other LCs and the aliphatic chains.

The absorbance was calculated using the optical relation $\mathrm{A}(\%)=100-\mathrm{T}(\%)-\mathrm{R}(\%)$.

\subsubsection{Thermographic Measurement}

Thermographic measurements of the PMP film during and after laser irradiation were performed using the LWIR camera AVIO TVS 500 (spectral range 8-14 $\mu$ m, FPA, $320 \times 240$, VOx microbolometer, Temperature resolution $\sim 0.05 \mathrm{~K}$, Yokoama, Japan) mounting a standard $22 \mathrm{~mm}$ lens. For temporal thermal trends the images were recorded with a frame rate of $20 \mathrm{~Hz}$. Emissivity of the film was set to 0.93 . All measurements were realized at a laboratory temperature of $23{ }^{\circ} \mathrm{C}$ and humidity of $50 \%$. 


\subsubsection{Atomic Force Microscopy (AFM)}

The AZO-LC-PMP-Z 6\% samples were morphologically characterized by atomic force microscopy. Analysis was carried out using the Veeco Dimension Digital Instruments Nanoscope IV (Plainview, NY 11803, USA) apparatus in the tapping mode configuration.

\subsubsection{Scanning Electron Microscopy and Energy Dispersive X-ray Analysis (SEM-EDX)}

The microstructural analysis of the PMPs was performed by SEM. The SEM-EXD analyses of the gold evaporated PMP films were carried out by using a field emission scanning electron microscope (FEG-SEM, Leo 1530 Gemini by Zeiss, Oberkochen, Germany) with an operating voltage of $10-12 \mathrm{kV}$.

\subsubsection{Wide Angle X-ray Diffraction (WAXS)}

Wide angle X-ray diffraction was used to analyze the crystal structure of samples (monomer powders and polymer films). The diffraction patterns were obtained with an automatic diffractometer (Philips X'PERT MPD) with $\mathrm{Cu}-\mathrm{K} \alpha$ radiation $(\lambda=1.54056 \AA$ ) in different configurations. A $\theta-2 \theta$ configuration was used for the monomer while the analyses of polymer samples were carried out in the thin-film configuration by fixing $\theta$ at $2^{\circ}$. For both types of measurements, $2 \theta$ was changed from $5^{\circ}$ to $60^{\circ}$, with a step of $0.05^{\circ}$ and $5 \mathrm{~s}$ of acquisition for each point.

\subsubsection{Polarized Optical Microscopy}

Olympus BX60 optical microscope (Tokyo, Japan) with crossed polarizers system and a magnification of $\times 10$ was used to characterize both polymer films and monomers. The images of monomers in mesophase were taken at $50^{\circ} \mathrm{C}$ by use of the temperature-controlled Linkam LTS120 stage.

\subsubsection{Dynamic Mechanical Analysis (DMA)}

Dynamic mechanical analysis was performed using a Triton Technologies dynamic mechanical analyzer (now Mettler Toledo DMA1, Columbus, OH, USA) in tension mode. Mechanical properties of the polymer films ( $5 \mathrm{~mm}$ (length) $\times 5 \mathrm{~mm}$ (width) $\times 0.06 \pm$ $0.005 \mathrm{~mm}$ (thickness)) were measured from $-20{ }^{\circ} \mathrm{C}$ up to breaking, at a heating rate of $3{ }^{\circ} \mathrm{C}$ min $^{-1}$ with an applied frequency of $1 \mathrm{~Hz}$. Samples were preloaded with $0.5 \mathrm{~N}$ stress to ensure sample stiffness during analysis $[52,53]$.

\subsubsection{Traction Ability}

The traction ability of the PMPs was measured using the Instron universal testing instrument (model No. 5543A, Instron Engineering Corp., Norwood, MA, USA) equipped with a $1 \mathrm{kN}$ cell. The samples were prepared as cantilevers with dimension of $30 \times 20 \mathrm{~mm}$ or $20 \times 15 \mathrm{~mm}$. Once positioned between the clamps in traction mode, the sample was hit with a $445 \mathrm{~nm}$ laser with a spot of $5 \times 1 \mathrm{~mm}$. The power density in the area hit with the laser was 2,4 or $1 \mathrm{~W} / \mathrm{m}^{2}$.

\subsubsection{Bending and Speed Characterization of PMPs}

To study the dynamic response of the PMPs, both bare and doped Azo-LC-PMP were cut as cantilevers $(5 \mathrm{~mm} \times 1 \mathrm{~mm})$ and irradiated at $457 \mathrm{~nm}$ with a 100:1 polarized laser. The laser wavelength was chosen according to the absorbance measurements carried out on the film and reported in Supplementary Figure S3 [27]. The set-up was composed of a neutral density filter, a retarder waveplate $(\lambda / 2)$, a focusing lens and a sample holder mounted on a 3D translator (Supplementary Figure S4).

The movements of the cantilevers were recorded at $60 \mathrm{fps}$. The videos have been unpacked using VLC (3.0.16) with the same frame velocity. The bending angle was measured considering the initial position of the cantilever with respect to its maximum bending. The angle was converted first to radian, then to arc length $(\mathrm{mm})$, and the speed calculated in $\mathrm{m} / \mathrm{s}$. The seconds were derived by considering the number of frames in which the can- 
tilever arrives to its maximum bending. Every speed point indicates the average bending speed during the path until the maximum bending.

\section{Results and discussion}

\subsection{Thermal and Optical Properties of the Monomer Mixture}

Before any polymerisation attempts, the thermal behaviour of the LC mixture was studied by using a DSC. The thermogram showed the first endothermic peak at $42{ }^{\circ} \mathrm{C}$ $\left(72 \mathrm{~J} / \mathrm{g}\right.$ ) and the second at $70^{\circ} \mathrm{C}(1.3 \mathrm{~J} / \mathrm{g})$ (Figure 1$)$. The first and strongest peak corresponds to the overlapping of different phenomena because of the destruction of the crystalline phases of the monomers. In contrast, the second peak corresponds to the formation of an isotropic phase in the mixture. Since the LCs were a complex mixture, we could speculate that the nematic phase could be reached anywhere between the two endothermic transitions. Subsequently, to have a better understanding of the nematic order of the mixture, the order parameter (S) was calculated. This is a quantitative evaluation that would help us to understand the optimal conditions to have the mixture in a nematic state. If the transition moment related to the absorption is oriented parallel to the molecular long axis, the order parameter $S$ can be calculated using the Equation (1).

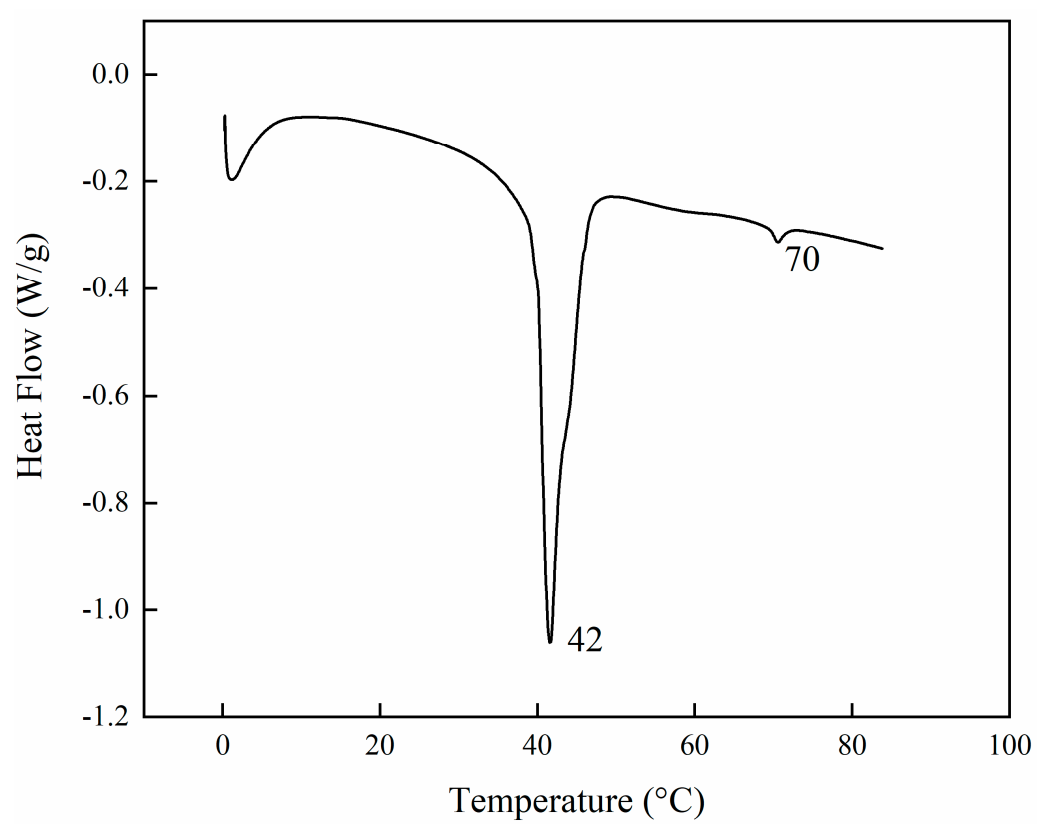

Figure 1. DSC profiles of LC monomer mixture melting when the initiator is absent. The thermogram corresponds to the first heating and shows two main endothermic transitions, the first at $42{ }^{\circ} \mathrm{C}$ and the second one at $70^{\circ} \mathrm{C}$.

Two different polarized lasers were used with wavelengths of $457 \mathrm{~nm}$ and $633 \mathrm{~nm}$. The laser at $457 \mathrm{~nm}$ was used to measure the orientational order of the mixture, showing a value of $S=0.5$ was generally found (in literature the $S$ is reported between 0.3 and 0.7) [54] (Figure 2A). Unfortunately, from these measurements it was only possible to define a range in which the mixture was in nematic state, between 40 and $60{ }^{\circ} \mathrm{C}$ (Figure 2A). In order to better define the range of the nematic phase, the transmittance at various temperatures was measured using the $633 \mathrm{~nm}$ laser. In particular, the measurements were taken in three different configurations when the director $\mathbf{n}$ was: (i) parallel to the analyzer, (ii) parallel to the polarizer and (iii) tilted by 45 degrees (the scheme of the setup is shown in supplementary Figure S1). From Figure 2B, it is clear that at $50{ }^{\circ} \mathrm{C}$ the mixture is at its highest order. In fact, the transmitted light has a maximum due to the ability to rotate the polarized light. 
(A)

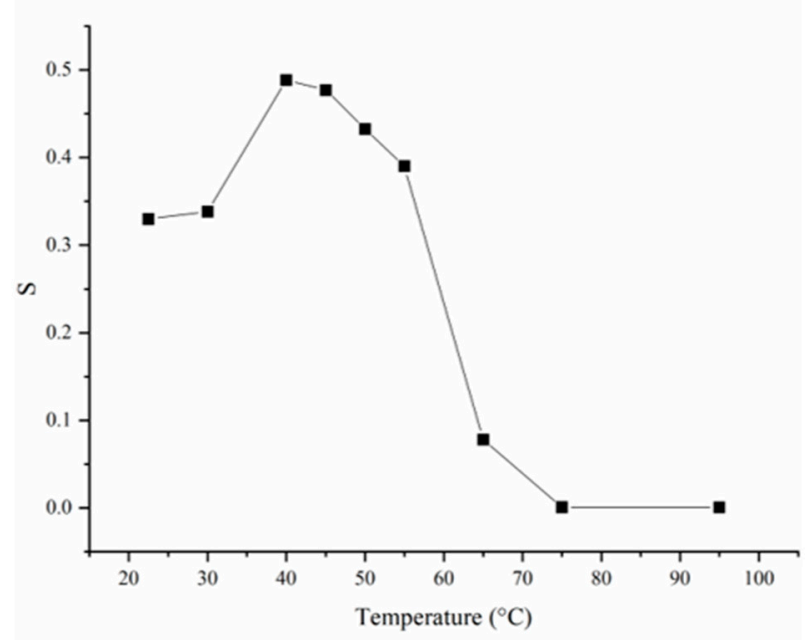

(B)

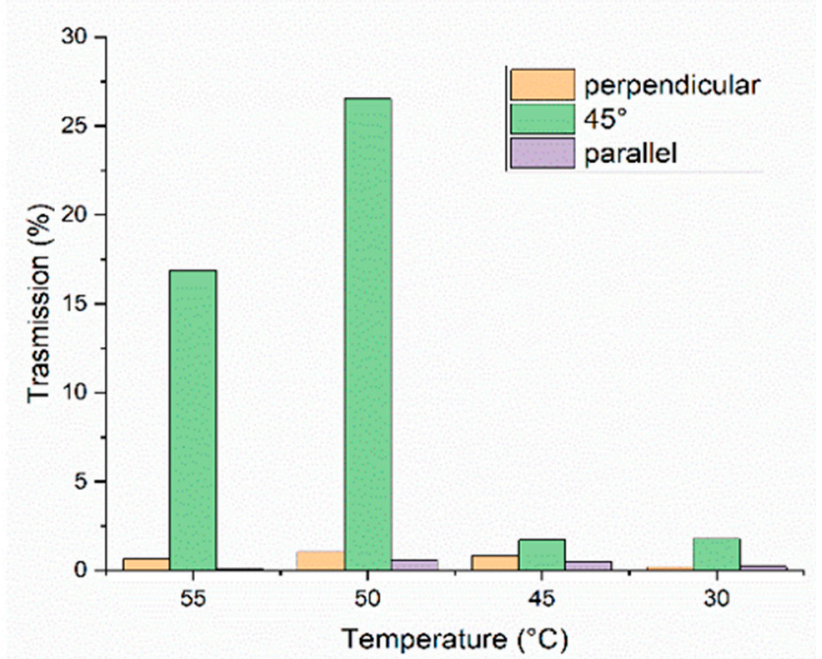

Figure 2. Order parameter experiment. (A) S calculated from transmission measurements vs. temperature with laser wavelength at $457 \mathrm{~nm}$. (B) Transmitted light vs. temperature and for different orientations of light polarization with respect to the direction $\mathrm{n}$ (laser wavelength at $633 \mathrm{~nm}$ ).

The monomers mixed with the nanoparticles could not be analysed due to the phase separation. In fact, because of the length of the experiment, the nanoparticle would phase separate because of the effects of gravity.

\subsection{Structural and Optical Characterizations of Photo-Mobile Polymers}

After the monomer infiltration, the PMPs were synthesized in rubbed reactor-cells, peeled off and characterized. As a preliminary step, the crystalline structures of bare and $\mathrm{ZnO}$ doped PMP samples were studied using X-ray diffractometry. The diffractograms of the PMP films were collected and compared with those of the starting monomers. As shown in Supplementary Figure S5, all the monomers are crystalline, while their spectra are complex and characterized by many crystalline reflections. The main crystalline peaks are centered at $14.9^{\circ}$ and $24.5^{\circ}$ for $\mathrm{A} 9 \mathrm{zA} 9$, and at $19.7^{\circ}$ and $21.5^{\circ}$ for the MAPE. The ACOB and AOBM present notably higher peaks than the others, respectively, at $25.3^{\circ}$ and $20.4^{\circ}$.

Crystalline reflections of the starting monomers are not visible in the diffractograms of bare (Azo-LC-PMP) and doped PMP (Azo-LC-PMP(6\%_Z)) films showing a complete polymerization for both formulations (Figure 3A,B). Indeed, independently from the orientation of the samples, all polymer spectra present a large peak at about $2 \theta$ of $22^{\circ}$ associated with polymer chains in an amorphous state. Moreover, for Azo-LC-PMP(6\%_Z) the amorphous spectra of the polymer were partially overlapped with the many, strong and narrow crystalline peaks of the $\mathrm{ZnO}$ nanoparticles. The peaks were centered at $31.9^{\circ}$, $34,6^{\circ}, 36.4^{\circ}, 47.8^{\circ}, 56.2^{\circ}, 63.0^{\circ}, 66.6^{\circ}, 68,1^{\circ}, 69,3^{\circ}$ corresponding to the lattice planes (100), (002), (101), (102), (110), (103), (112), (112) and (201) of the wurtzite structure of ZnO.

Later, the PMPs were analysed with a polarized light microscope to find out if the nematic phase was stored after polymerization. The objective used was $10 \times$, and the film was set both at 45 degrees and parallel to one of the two polarizers. The Azo-LC-PMP showed a well-defined property of rotation of polarized light (Figure 4A,B). This was confirmed by measuring the power of the light observed when the samples were rotated at different angles with respect to the two polarizers. A maximum transmission was measured when the cell was tilted of 45 degrees (Table 1). This result is an indication that our procedure allowed the synthesis of crosslinked films that have orientational ordering of the LC moieties. 

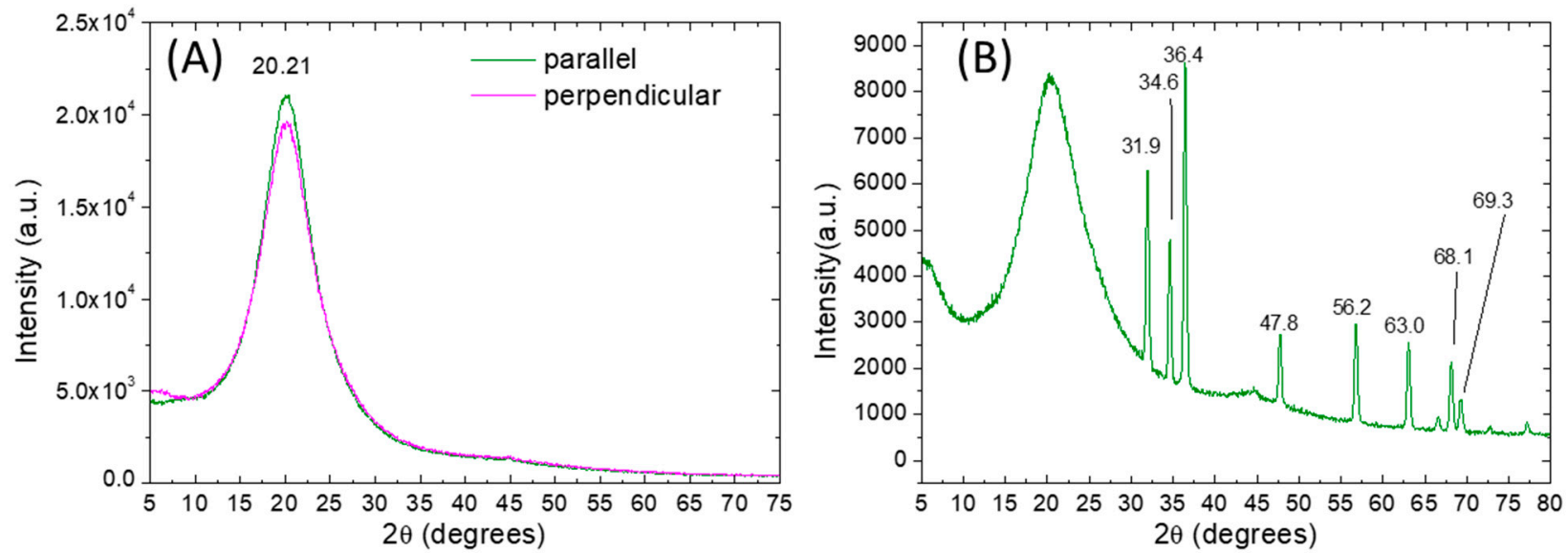

Figure 3. X-ray diffraction patterns $(\mathrm{Cu} \mathrm{K} \alpha)$ of undoped AZO-LC-PMP (A) and doped AZO-LC-PMP-Z6\% (B). For the undoped film the spectra are obtained by orienting the sample in two different ways (with the rubber direction parallel or perpendicular to the X-ray source).
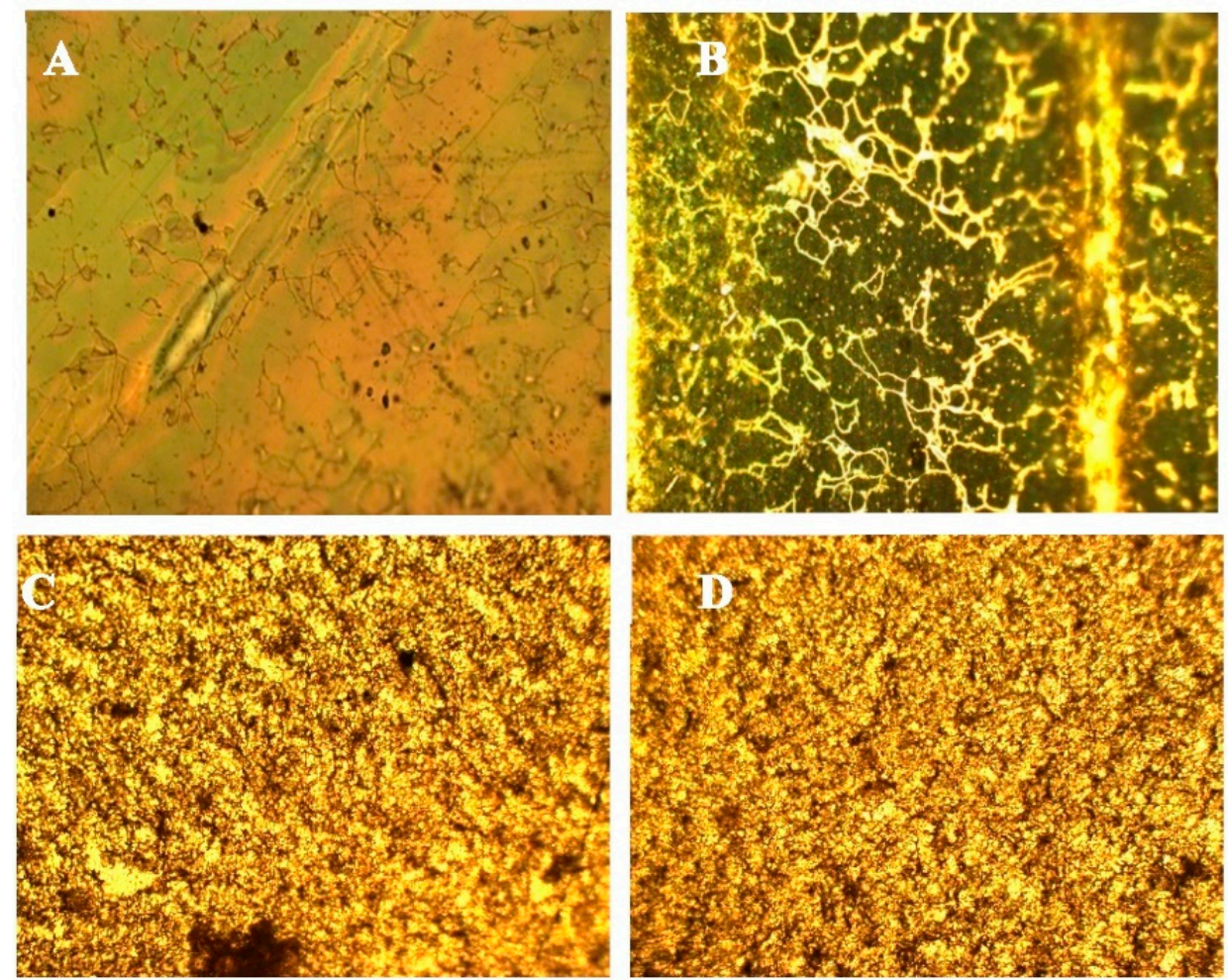

Figure 4. Optical images of Azo-LC-PMP (A,B) and doped PMP (C,D) obtained by polarized light microscope measured by putting the respective samples at 45 degrees $(\mathbf{A}, \mathbf{C})$ or parallel to one of the two polarizers (B,D).

Table 1. Transmissivity of bare and doped PMP when the director $\mathbf{n}$ was parallel to the polarizers or tilted by 45 degrees, with incident light power $P_{\text {in }}=2.5 \mathrm{~mW}$.

\begin{tabular}{cccc}
\hline Sample Name & $\begin{array}{c}\text { Parallel to Polarizer } \\
(\mu \mathbf{W})\end{array}$ & $\begin{array}{c}\text { Tilted by 45 Degrees } \\
(\mu \mathbf{W})\end{array}$ & $\begin{array}{c}\text { Parallel to Analyzer } \\
(\boldsymbol{\mu W})\end{array}$ \\
\hline Azo-LC-PMP & 15.5 & 403 & 24.2 \\
\hline Azo-LC-PMP doped & 0.92 & 0.62 & 0.45 \\
\hline
\end{tabular}


For doped PMPs, no nematic alignment was detected. When the birefringence was tested, no significant difference was noted between the various configurations and formulations (Figure 4C,D, Table 1). This result shows that the ZnO-doped PMPs did not show orientational organization.

Together with polarized microscopy, in order to investigate the particles' organization inside and outside the PMPs, SEM and AFM microscopy were performed.

As highlighted by SEM (Figure 5) and standard optical microscopy (Supplementary Figure S6) aggregates (of size about 1.5-2 $\mu \mathrm{m}$ ) are clearly visible on the surface of the doped PMP films at low magnification. The distribution of the aggregates seems not to be random. In fact, a higher concentration of them was observed along the rubbing direction (Figure 5A,B). The formation of particle trails of various sizes and length between the various clusters was detected both in the polymerised PMP and in the monomer melt (Supplementary Figure S7). The presence of these big aggregates suggests that a partial uncontrolled aggregation process has happened during the polymerization. It will be an object of further study in the future to minimize the occurrence of this process and improve the uniform dispersion of the $\mathrm{ZnO}$ in the samples.
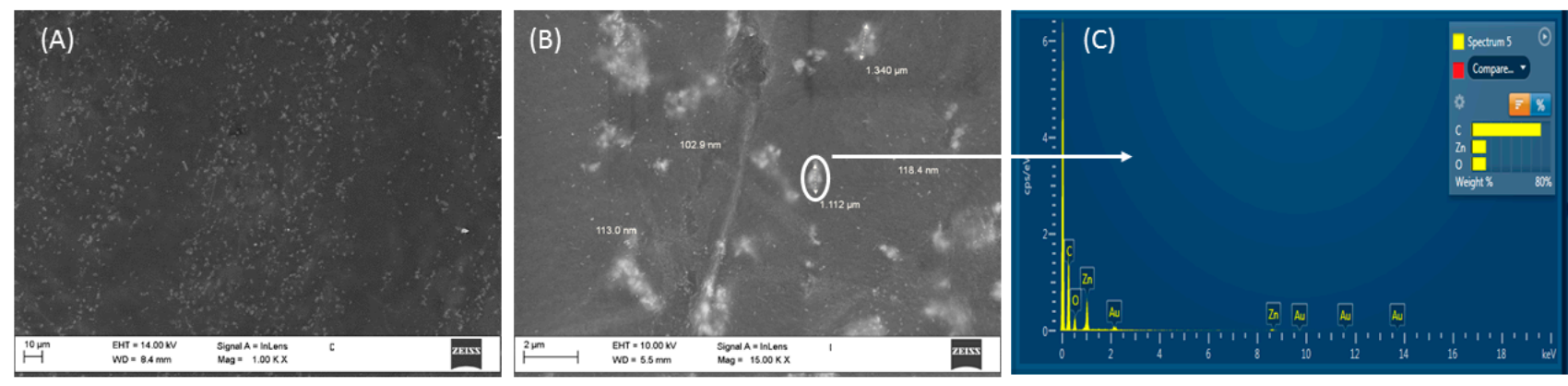

Figure 5. SEM images at different magnification of Azo-LC-PMP-Z6\% (A,B) and an example of qualitative EDX analysis (C) carried out on the sample in correspondence of the aggregate indicated in B.

SEM analysis at a higher magnification (Figure 5B) highlights the complex structures of the aggregates that consist of a collection of smaller nanoparticles as shown in Figure $5 \mathrm{~B}$. The qualitative analysis of the aggregates, carried out by EXD, confirms the presence of atoms of $\mathrm{Zn}$ and $\mathrm{O}$, not detected in the adjacent areas.

From Figure 5B, it is also possible to observe the presence of a large number of smaller $\mathrm{ZnO}$ particles with diameters lower than $110 \mathrm{~nm}$. The distribution of these particles was investigated more deeply by AFM.

Figure 6 shows topographic and phase contrast AFM images of the ZnO-doped PMP and bare PMP films. Topographic imaging of the composite-based sample clearly displays $\mathrm{ZnO}$ nanoparticles dispersed in the polymer matrix, almost uniformly distributed on the whole scanned area (Figure 6A). The root-mean-square roughness ( $\mathrm{Rq}$ ) valuated on the $5 \times 5 \mu \mathrm{m}^{2}$ surface gave a result equal to $14.02 \mathrm{~nm}$. As expected, the AFM analysis of the undoped PMP, studied as a comparison, shows a flatter surface characterized by the $\mathrm{Rq}$ value estimated to be equal to $5.11 \mathrm{~nm}$. In addition, phase images are also shown to uncover further details of the investigated morphologies: the phase, basically produced by the changes in adhesion between the tip and the sample surface, confirms nanostructures only with $\mathrm{ZnO}$-doped PMP film (Figure 6B) and some of them are covered by (due to phase contrast generated by topographic variations) and others emerge from (due to phase generated by both topographic and compositional variations) the surrounding polymer. For the bare PMP sample, the phase image only reflects the surface topography and its inhomogeneities. 

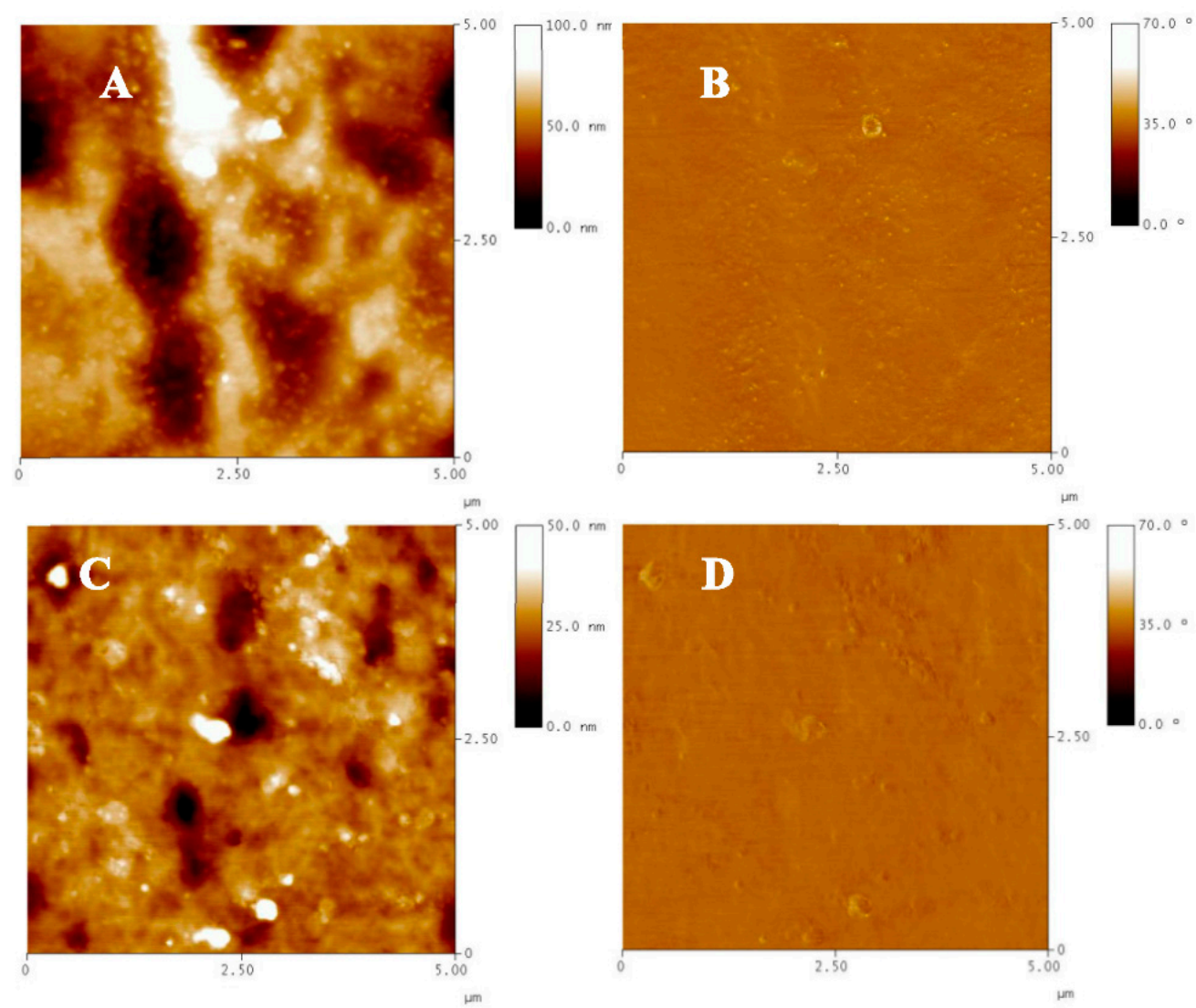

Figure 6. Topography and phase AFM images of $\mathrm{ZnO}$-doped PMP (A,B) and bare PMP (C,D) films detected by scanning $5 \times 5 \mu \mathrm{m}^{2}$-sized areas.

Three-dimensional imaging (Supplementary Figure S8) provides an informative view of the top surface of the doped PMP film studded with NPs.

The nanostructures observed on the surface of the composite-based film are organized as nanoaggregates with an estimated average size of about $100 \mathrm{~nm}$, and mostly as single nanoparticles having an average diameter of $40-50 \mathrm{~nm}$. The latter are more noticeably distinguishable by zooming the observation up to $2 \times 2 \mu \mathrm{m}^{2}$ areas (Supplementary Figure S9A). By imaging larger areas, the nanostructures' distribution on the surface was highlighted. Independently of the poor surface homogeneity, it appears that the nanostructures are uniform along the rubbing direction (vertical direction of the $10 \times 10 \mu \mathrm{m}^{2}$-sized image) (Supplementary Figure S9B).

\subsection{Thermomechanical Properties of PMPS}

After the morphological analysis, the PMPs were characterized for their thermomechanical properties. At first, a scan TGA experiment was performed to study the thermal stability of the samples (Figure 7).

Concerning the thermal stability of the samples, degradation of the bare PMP starts at about $367^{\circ} \mathrm{C}$, about $20 \%$ of weight loss occurred up to $404{ }^{\circ} \mathrm{C}$, then subsequent heating leads to complete degradation of the material in the range of $404-700{ }^{\circ} \mathrm{C}$. The presence of $\mathrm{ZnO}$ nanoparticles did not alter the thermal stability of the polymer in terms of degradability, since the onset degradation temperature of the nanocomposite is $369^{\circ} \mathrm{C}$ and the temperature corresponding to the maximum weight loss of the first degradation step, $T_{d 1}$, is $409^{\circ} \mathrm{C}$. The second degradation step was shifted towards a lower temperature in the doped sample compared to the plain polymer. As expected, there is no difference between the two samples except for the final weight at the end of the process. In fact, for the Azo-LC-PMP(6\%_Z) there is $6 \%$ more residue because of the $\mathrm{ZnO}$ nanoparticles (Figure 7). 


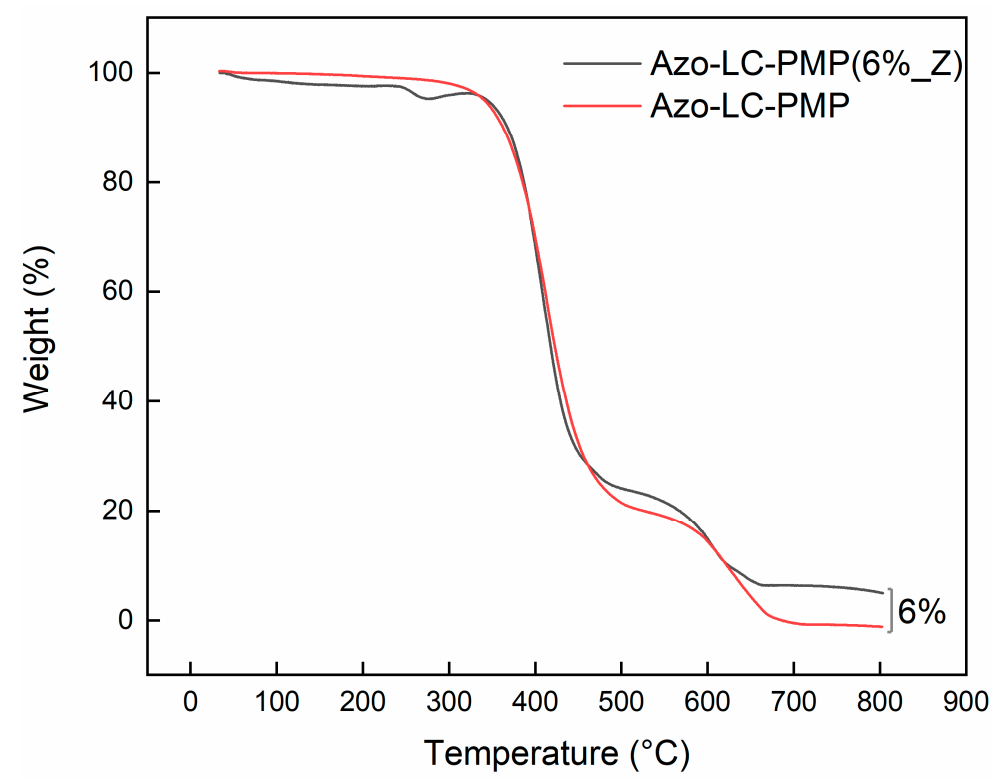

Figure 7. Thermogravimetric analysis of bare and doped PMP film, showing the degradation as a function of the temperature.

The Azo-LC-PMP DSC-thermogram displayed a glass transition $\left(T_{g}\right)$ at $36.4^{\circ} \mathrm{C}$. Glass transition of the $\mathrm{ZnO}$ nanocomposite, centred at $40.7^{\circ} \mathrm{C}$, is slightly shifted towards higher temperatures (Supplementary Figure S10). The presence of well-dispersed $\mathrm{ZnO}$ nanoparticles could reduce the segmental mobility of the polymeric chains at the interface, thus shifting the $T_{g}$ of the nanocomposite.

Besides this, in order to understand if $\mathrm{ZnO}$ nanoparticles would affect the thermomechanical response of the materials, the PMPs were tested using a DMA in a gradient of temperature. When the storage modulus $\left(G^{\prime}\right)$ of the two materials was compared, a higher $\mathrm{G}^{\prime}$ was recorded for Azo-LC-PMP $(6 \%$ _Z). In fact, it was more stable temperaturewise and twofold higher for Azo-LC-PMP (6\%_Z) compared to Azo-LC-PMP (Figure 8A). Increasing the temperature from $0{ }^{\circ} \mathrm{C}$, the bare PMP storage modulus began to decrease as the temperature approached $35^{\circ} \mathrm{C}$. For the Azo-LC-PMP $(6 \%$ Z $)$ the storage modulus remained stable around $2 \mathrm{GPa}$ up to the rubbery zone in the same temperature range. The glass transition temperature increases for the composite material, as shown by the TanDelta (calculated as the ratio between storage and loss moduli) (Figure 8B) and confirmed in the DSC (Supplementary Figure S10). The $T_{g}$ increase is most likely partially because of nanoparticles in high concentration [55]. In fact, as mentioned above, the chain end of the polymer would be hindered by the particles and would have difficulties vibrating during the DMA experiment.

Another result that showed the superior properties of the composite PMP compared to the bare version was the measuring of the traction ability of the films reported in Figure 9. The PMPs were irradiated while clamped to a dynamometer. The Azo-LC-PMP(6\%_Z), when irradiated with $2.5 \mathrm{~W} / \mathrm{cm}^{2}$, was able to express a higher force when at plateau (275 Pa) compared to the bare film (200 Pa). Furthermore, when the PMPs were irradiated with a laser power as low as $1 \mathrm{~W} / \mathrm{cm}^{2}$, only Azo-LC-PMP $(6 \%$ ZZ) was able to produce some force. It is important to note that such an experiment was performed irradiating PMPs on a small area $\left(0.05 \mathrm{~cm}^{2}\right)$ compared to the total area of the PMPs $\left(\mathrm{x} \mathrm{cm}^{2}\right)$. 

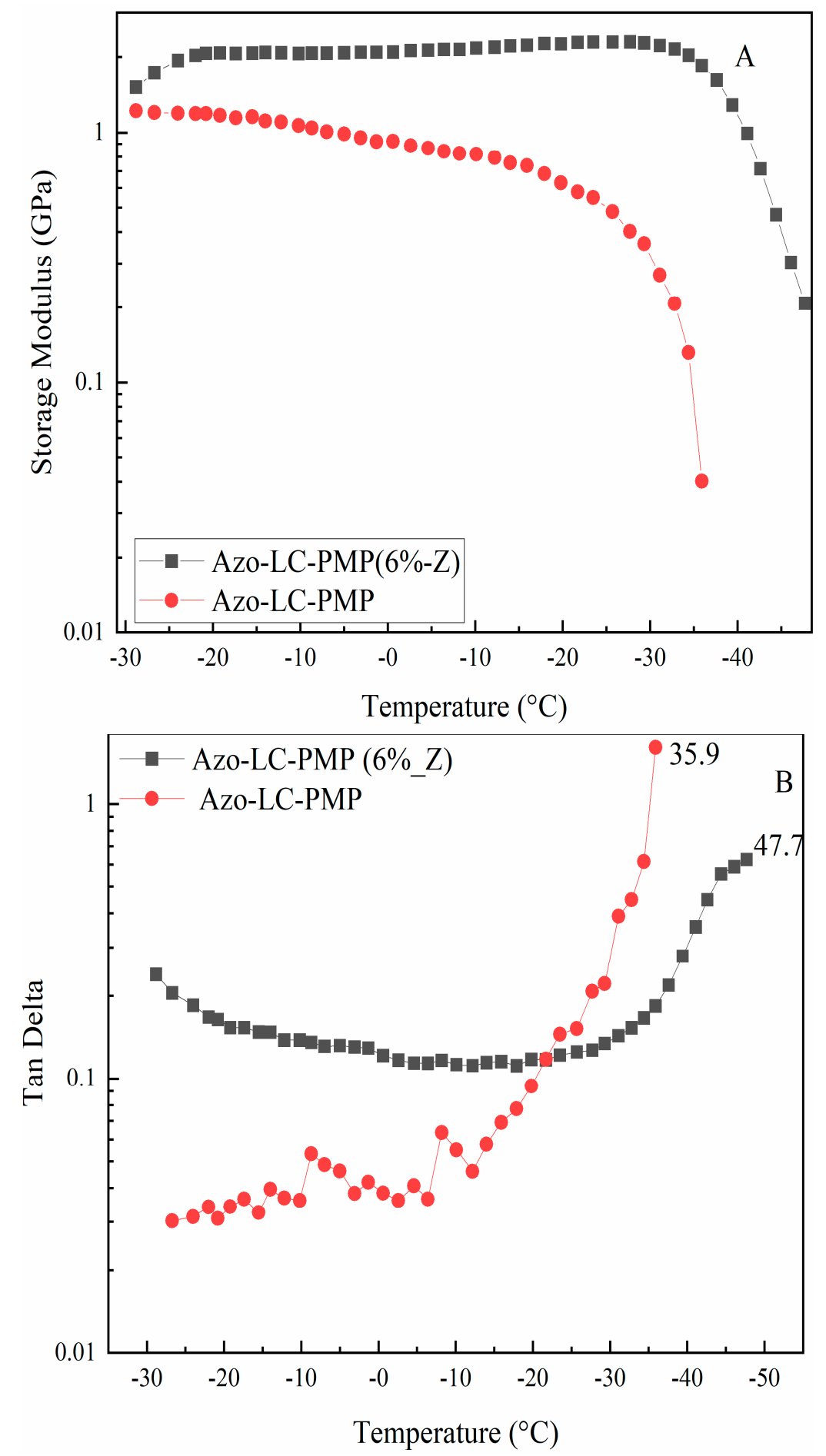

Figure 8. Dynamic mechanical analysis of Azo-LC-PMP amd Azo-LC-PMP(6\%_Z). (A) Comparison of storage modulus of the two formulations (B) TanDelta comparison of the Azo-LC-PMP $(6 \%$ Z $)$ and Azo-LC-PMP. 


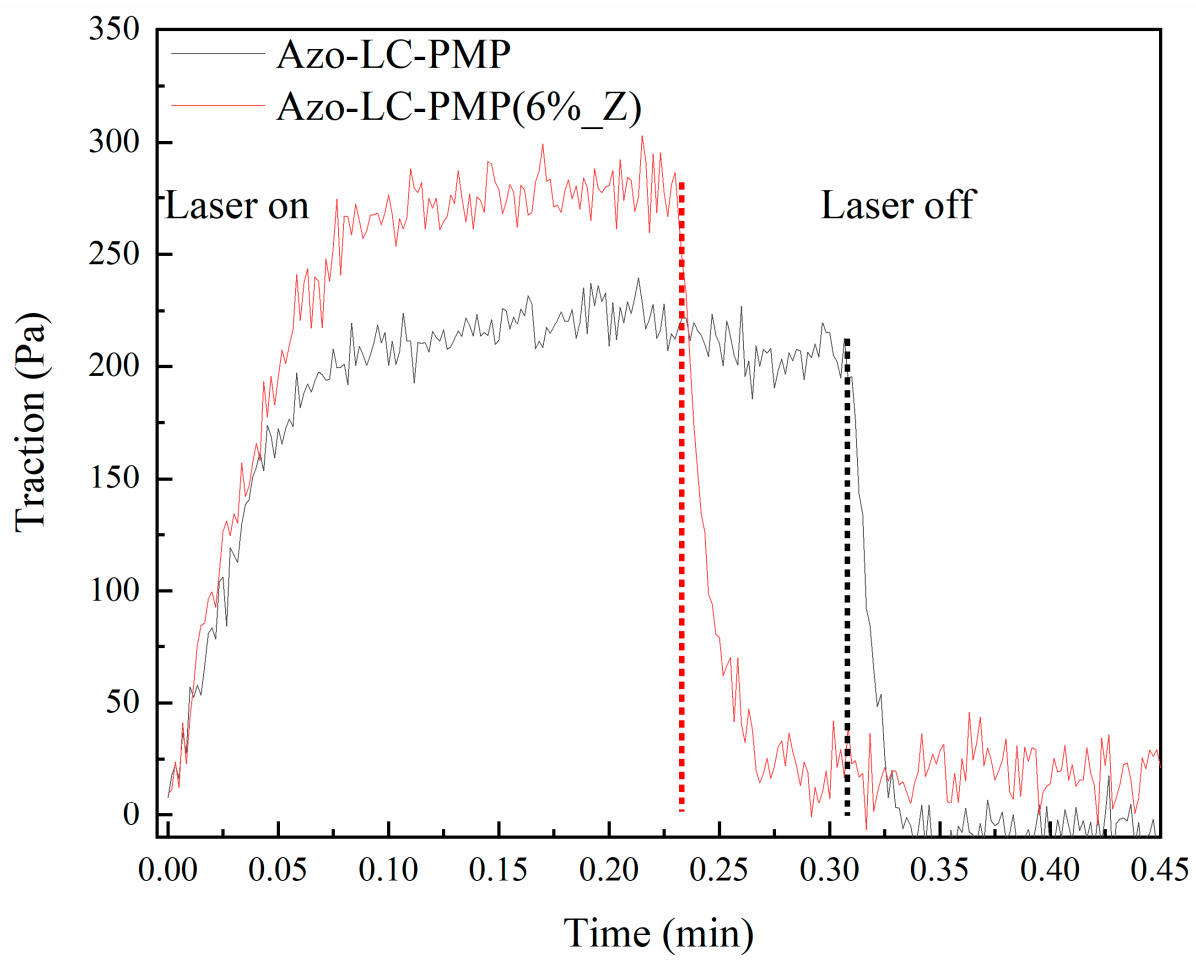

Figure 9. Traction ability of the PMPs when irradiated by the laser. The power density was $2.4 \mathrm{~W} / \mathrm{cm}^{2}$. The laser starts to irradiate the sample at $0.0 \mathrm{~min}$ and stops on the dotted line.

\subsection{ZnO Nanoparticles Effect on Azo-LC-PMP/Light Interaction}

The bare PMPs were optimized as previously described and then optically characterized to investigate their performance by a test of self-vibration as described in the literature [5,51]. The cantilever-shaped PMPs were irradiated with a $457 \mathrm{~nm}$ laser with a laser-spot with a radius of $0.5 \mathrm{~mm}$. The power density $\left(\right.$ area $\left.=0.008 \mathrm{~cm}^{2}\right)$ was modulated in a range between 1 and $10 \mathrm{~W} / \mathrm{cm}^{2}$. The power threshold to bend the film synthesized at $50{ }^{\circ} \mathrm{C}$ (Figure 10A) was $1 \mathrm{~W} / \mathrm{cm}^{2}$ and the self-oscillating threshold was $7.5 \mathrm{~W} / \mathrm{cm}^{2}$ (Supplementary Figure S11A). To show that the optimized Azo-LC-PMP, cured at a nematic temperature $\left(50^{\circ} \mathrm{C}\right)$, performed better than formulations prepared at higher temperatures, it was compared with one prepared at $60^{\circ} \mathrm{C}$ (Supplementary Figure S11B). Indeed, already at $4 \mathrm{~W} / \mathrm{cm}^{2}$ the speed of Azo-LC-PMP was 7.8 -fold higher than the one polymerized at higher temperature (Supplementary Figure S11B). These results confirm the importance of studying the thermal and optical properties of a new monomer mixture in order to detect its nematic temperature optimizing the long-range order in bare PMP films.

Afterward, the bending properties of Azo-LC-PMPs (manufactured at $50{ }^{\circ} \mathrm{C}$ ) were studied to understand if the nanoparticles would affect their light response. The polymer films were tested for their bending speed, bending capability and response threshold to light irradiation. The Azo-LC-PMP $(6 \%$ Z Z) performed better than Azo-LC-PMP both in terms of maximum bending angle and bending speed (Figure 10). The power threshold to move the doped sample was again $1 \mathrm{~W} / \mathrm{cm}^{2}$. Interestingly, at $1 \mathrm{~W} / \mathrm{cm}^{2}$, bending of the composite film was eight times higher than the Azo-LC-PMP film (Figure 10A). At this power density, the speed was nine times higher. The speed difference decreases with an increase in the power density. At the maximum measured power density $\left(12 \mathrm{~W} / \mathrm{cm}^{2}\right)$ the doped PMPs had a speed about two times higher (Figure 10B). 

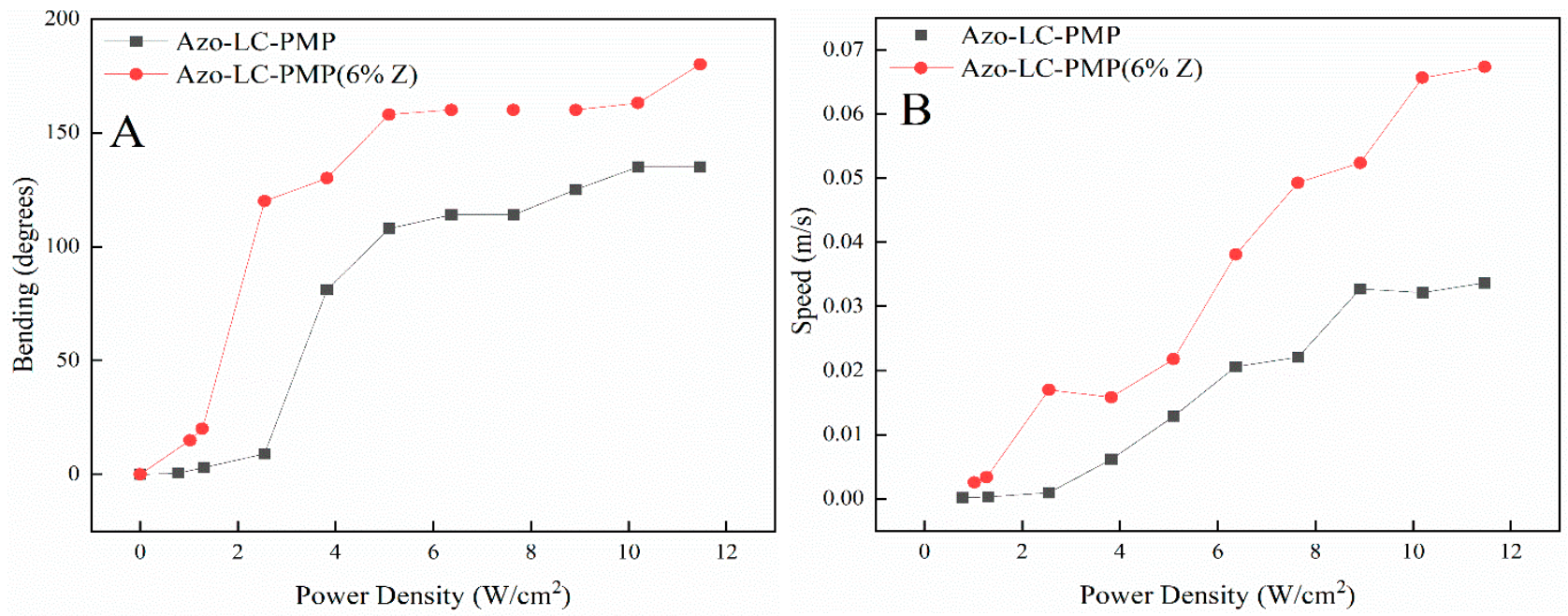

Figure 10. Comparison between the maximum bending (A) and speed (B) of Azo-LC-PMP and ZnO doped AZO-LC-PMP films. The graphs show the increased efficiency of the doped PMPs in terms of bending and speed.

Thermal and spectral characterization were performed to understand the nature of the observed effect.

In Figure 11A,B the UV/vis characterizations of the bare and doped PMPs are reported. Both Azo-LC-PMP and Azo-LC-PMP(6\%_Z) present an absorbance that goes approximately up to $95 \%$ in the wavelength range of 300-400 nm. In contrast, for Azo-LC-PMP(6\%_Z), an increase of absorption was recorded with a range between $400 \mathrm{~nm}$ and $500 \mathrm{~nm}$ (Figure 11A). For example, the absorbance at $457 \mathrm{~nm}$ shows an increase of $40 \%$ compared to Azo-LC-PMP. This probably allows the PMP to absorb higher amounts of radiation in a region other than UV (Figure 11A). The increase in absorbance is probably due to the high reflectivity of the $\mathrm{ZnO}$ nanopowder [56] embedded inside the PMP. In fact, these kinds of nanoparticles are also used in scattering layers for different applications [56].
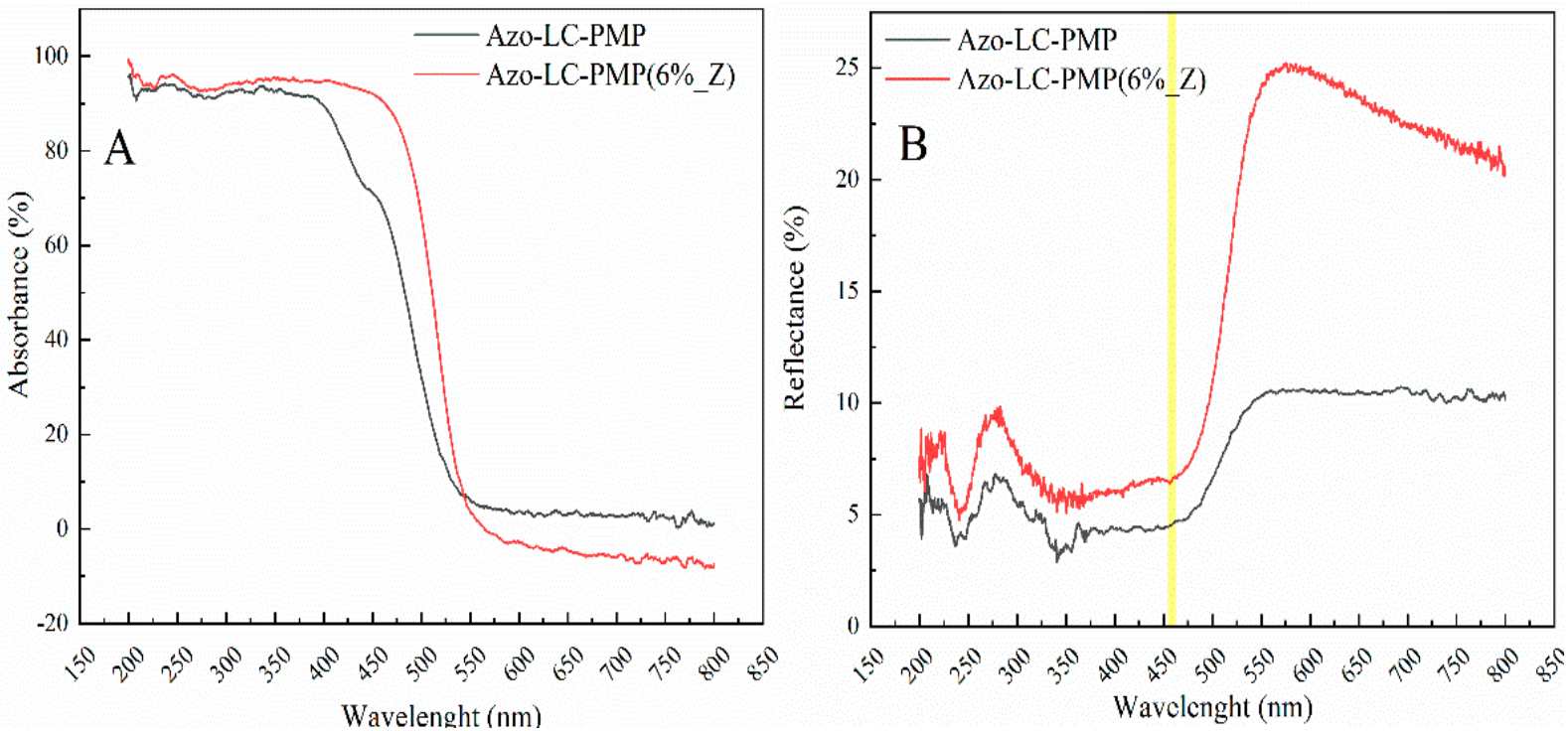

Figure 11. Comparison between the spectra of (A) absorbance, and (B) reflectance of both Azo-LC-PMP and doped Azo-LC-PMP Z.

The total reflectance at $457 \mathrm{~nm}$ shows an increase of $2.5 \%$ for Azo-LC-PMP(6\%_Z). When higher wavelengths are considered (550-800), the reflectance shows a noticeable increase, confirming that particles also appear on the PMP surface as shown with the SEM and AFM (Figures 5 and 6). 
Additionally, the spectral analysis showed another interesting behavior of Azo-LCPMP $(6 \%$ Z $)$ related to the extinction of the cis isomer of the azobenzene. In fact, when the $\mathrm{ZnO}$ is embedded into the PMP matrix, the cis isomer isomerizes back into trans in a shorter time. After an irradiation of $15 \mathrm{~min}$ with the UV lamp and a dark period of $1 \mathrm{~h}$, the concentration of cis isomers in the Azo-LC-PMP is 7\% higher than in AzoLC-PMP $(6 \%$ Z) (Supplementary Figure S3). This effect was previously attributed to an exchange of electrons between metal and azobenzene, when gold nanoparticles were embedded in the PMP $[29,35]$.

The thermal behavior of PMP films both with and without $\mathrm{ZnO}$ particles under laser irradiation $(\lambda=457 \mathrm{~nm})$ was investigated and compared by means of thermographic analysis. In Figure 12A, the temperatures measured for the two films at a density power irradiation ranging between $0-11.5 \mathrm{~W} / \mathrm{cm}^{2}$ are reported. The temperatures refer to values achieved after $10 \mathrm{~s}$ of irradiation in the condition of thermal equilibrium. Each value represents an average estimated on a film area of $2 \mathrm{~mm}^{2}$.

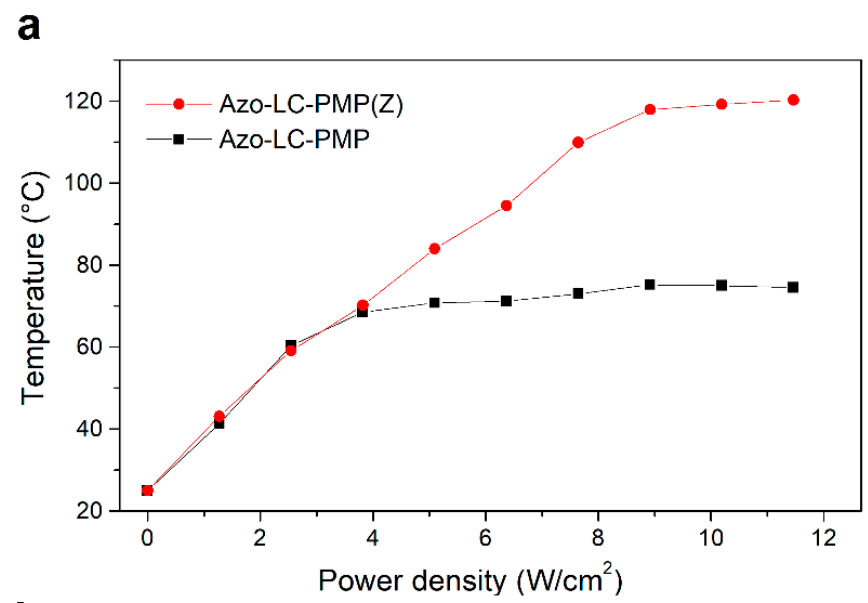

b

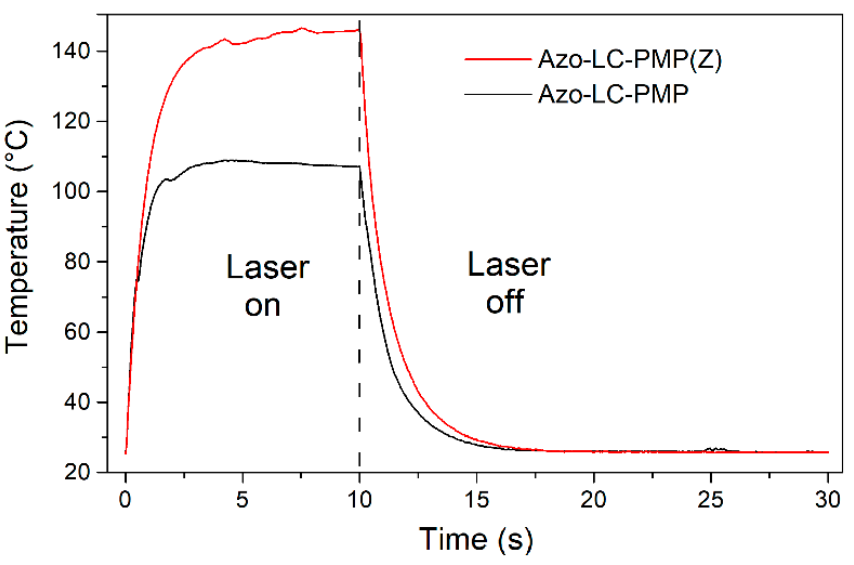

Figure 12. Thermographic measurements of the undoped (black color) and doped (red color) PMP film: (a) temperature at the equilibrium condition versus the power density of the laser irradiation, (b) temporal trend of the temperature during and after laser irradiation with a power density of $11.5 \mathrm{~W} / \mathrm{cm}^{2}$.

The trend of the two films is similar up to the power density of about $3 \mathrm{~W} / \mathrm{cm}^{2}$ (corresponding to a film temperature of about $65^{\circ} \mathrm{C}$ ). The effect of the particles up to these values appears negligible. At a higher power density, the effect of the $\mathrm{ZnO}$ particles appears clear. While the undoped PMP film shows a plateau around $75{ }^{\circ} \mathrm{C}$, the temperature of the doped PMPs continues to increase linearly up to a maximum value of about $120^{\circ} \mathrm{C}\left(11.5 \mathrm{~W} / \mathrm{cm}^{2}\right)$. This last result shows how the presence of $\mathrm{ZnO}$ particles favors the absorption of the 
radiation, thus increasing the heat absorbed by the PMP film, above a certain threshold $\left(3 \mathrm{~W} / \mathrm{cm}^{2}\right)$.

Interestingly, comparing the temperature trend (Figure 12) of Azo-LC-PMP(Z) with its speed (Figure 10B), the two quantities seem to be correlated. This shows that heat plays an important role in improving the performance of the doped PMP.

In Figure 12B, the temporal response of the temperature of both doped and undoped film is shown when they are irradiated with the same laser source for $10 \mathrm{~s}$ and with a power density of $11.5 \mathrm{~W} / \mathrm{cm}^{2}$. As expected, because of the metallic inclusions, the temperature rate of the doped PMPs is higher with respect to bare PMPs in both heating and cooling phases. During the heating phase, the rate is about $93{ }^{\circ} \mathrm{C} / \mathrm{s}$ for the bare PMPs and about $107^{\circ} \mathrm{C} / \mathrm{s}$ for the doped one. In contrast, during the cooling phase, the rates are about $11^{\circ} \mathrm{C} / \mathrm{s}$ for undoped film and $16^{\circ} \mathrm{C} / \mathrm{s}$ for the PMPs with the $\mathrm{ZnO}$. Moreover, the trend of the bare PMPs reaches a plateau at a temperature of $107^{\circ} \mathrm{C}$ while the doped film reaches a maximum temperature of $146^{\circ} \mathrm{C}$. At those temperatures, the undoped film starts to burn while the doped film does not, indicating a possible dissipation effect due to the metal oxide.

As briefly mentioned, there is a correlation between the bending of the PMPs, their response to light stimuli, and induced thermal effects. In fact, when the temperature reaches the plateau for the Azo-LC-PMP (Figure 12A, $4 \mathrm{~W} / \mathrm{cm}^{2}$ ), the bending has a constant value (Figure 10A, 100 degrees) until a slight flex in the temperature is recorded (Figure 12A, $\left.8 \mathrm{~W} / \mathrm{cm}^{2}\right)$ and the bending starts to increase again. When Azo-LC-PMP $(6 \%-Z)$ is analyzed, the bending becomes constant $(\sim 150$ degrees $)$ at a higher temperature $\left(90^{\circ} \mathrm{C}\right)$ indicating that the presence of metallic nanoparticles would cause a thermotropic effect. This correlation is observed for the speed of the PMPs too. Our hypothesis is that an azobenzene photoisomerization equilibrium (trans-cis-trans) is reached. In fact, the laser induces the trans to cis isomerization and instead, heat induces the inverse process.

Further behavior worth noting is related to the linear increase of the PMP speed for the Azo-LC-PMP(6\%_Z) (Figure 10A). In fact, the speed of the doped PMP is always higher, and it increases linearly. This is possibly correlated with an increase in temperature in the irradiated area, causing a softening of the polymer in that spot. This effect would help the bending and velocity without affecting much the mechanical properties (Figure 8A) that were improved because of the presence of $\mathrm{ZnO}$.

\section{Conclusions}

A liquid crystal mixture doped with $\mathrm{ZnO}$ nanoparticles was characterized to evaluate its use in the synthesis of novel efficient PMPs. We demonstrated that our facile method for the fabrication of the PMPs was highly reproducible and allowed the formation of a distributed nanoparticles network in the film. The nanoparticles were present both as a fine dispersion and clusters and, interestingly, were distributed throughout the whole film and not only in the surface.

The addition of nanoparticles to the PMP improved the mechanical properties of the material. In fact, the $G^{\prime}$ measured using a DMA was two times higher and more stable between -10 and $40{ }^{\circ} \mathrm{C}$. Furthermore, the $T_{g}$ increased considerably.

Spectroscopic and thermal behavior of doped photomobile films was deeply investigated by means of UV-VIS spectroscopy and thermographic experiments. Focusing on a wavelength region (around $457 \mathrm{~nm}$ ) where the absorption band of the undoped mixture start to decrease $(\geq 70 \%)$, we demonstrated the possibility to increase light absorption, expanding the bandwidth in which the PMPs could properly work. Comparing doped and bare PMPs, it is clear that the improvement in efficiency in terms of light conversion into mechanical movement is due to the $\mathrm{ZnO}$ nanoparticles that strongly modify both the spectral and thermal properties of the fabricated films.

Supplementary Materials: The following are available online at https:/ / www.mdpi.com/article/10 $.3390 /$ nano11123320/s1, Figure S1: Setup for the measurement of transmitted light and birefringence. Figure S2: (Up) Preparation of glass reactor cells and polymerization. (down) Monomer and Polymer 
structure. Figure S3: (A) Absorbance of the azobenzene moieties embedded in the PMP, obtained by subtracting the contribution of the other elements in the PMP (B) Absorbance of azobenzene moieties in trans post irradiation, obtained subtracting the absorbance of the PMP pre-UV. Figure S4: Setup for characterization of PMPs light response. Figure S5: X-ray diffraction patterns $(\mathrm{Cu} \mathrm{K} \alpha)$ of the starting monomer powders. Figure S6: Picture of melted monomer penetrated in the cell (left) and outside the cell(right). In both the pictures it is possible to see trails formed by the interaction of nanoparticles and LCs. Objective $10 \times$. Figure S7. Aggregates and trails formed by nanoparticles. On the left a closeup picture $(100 \times)$ of a cell-like structure in a Azo-LC-PMP $(6 \%-Z)$ and on the right a Azo-LCPMP $(1 \%-\mathrm{ZnO})$ mixture showing the aggregates and trails $(10 \times)$. Figure S8: 3D-topography AFM image of $\mathrm{ZnO}$-doped PMP film detected by scanning $5 \times 5 \mu^{2}$-sized area. Figure S9: Topography AFM images of ZnO-doped PMP film detected by scanning $2 \times 2 \mu \mathrm{m}^{2}$ (A) and $10 \times 10 \mu \mathrm{m}^{2}$ (B) -sized areas. Figure S10: DSC Thermograms of Azo-LC-PMP and ZnO composite scans. Figure S11: (left) Self-Oscillating Azo-LC-PMP without $\mathrm{ZnO}$ nanoparticles (right) Bending speed (m/s) of Azo-LC-PMP Z polymerized at $50{ }^{\circ} \mathrm{C}$ and $60^{\circ} \mathrm{C}$. Showing the improved performance of the film when polymerized at the nematic temperature.

Author Contributions: D.S. idea, experimental, draft, writing, supervision; M.C. (Marcella Calabrese) experimental, O.K. experimental, draft; M.R. experimental, draft; A.V. experimental, draft; V.M. experimental, draft; F.L. experimental, draft; F.V. experimental, draft; K.K. experimental; V.C.C. draft; V.A. draft; K.M. draft; M.C. (Mariacristina Cocca) Experimental, draft; G.N. draft, supervision; C.B. experimental; F.S. draft revision; L.P. project coordinator, draft revision, supervision. All authors have read and agreed to the published version of the manuscript.

Funding: This project has received funding from the European Union's Horizon 2020 research and innovation programme under H2020-FETOPEN-2018-2019-2020-01Call.

Data Availability Statement: Not applicable.

Acknowledgments: The authors thanks Loredana Mariniello for the support and insightful comments on mechanical properties measurements.

Conflicts of Interest: The authors declare no conflict of interest. The funders had no role in the design of the study; in the collection, analyses, or interpretation of data; in the writing of the manuscript, or in the decision to publish the results.

\section{References}

1. Yamada, M.; Kondo, M.; Mamiya, J.; Yu, Y.; Kinoshita, M.; Barrett, C.J.; Ikeda, T. Photomobile Polymer Materials: Towards Light-Driven Plastic Motors. Angew. Chem. 2008, 120, 5064-5066. [CrossRef]

2. He, J.; Zhao, Y.; Zhao, Y. Photoinduced bending of a coumarin-containing supramolecular polymer. Soft Matter 2009, 5, 308-310. [CrossRef]

3. Mamiya, J.I.; Kuriyama, A.; Yokota, N.; Yamada, M.; Ikeda, T. Photomobile polymer materials: Photoresponsive behavior of cross-linked liquid-crystalline polymers with mesomorphic diarylethenes. Chem.-A Eur. J. 2015, 21, 3174-3177. [CrossRef]

4. Ube, T.; Ikeda, T. Photomobile Polymer Materials with Crosslinked Liquid-Crystalline Structures: Molecular Design, Fabrication, and Functions. Angew. Chem. Int. Ed. 2014, 53, 10290-10299. [CrossRef] [PubMed]

5. White, T.J.; Tabiryan, N.V.; Serak, S.V.; Hrozhyk, U.A.; Tondiglia, V.P.; Koerner, H.; Vaia, R.A.; Bunning, T.J. A high frequency photodriven polymer oscillator. Soft Matter 2008, 4, 1796-1798. [CrossRef]

6. Kondo, M. Photomechanical materials driven by photoisomerization or photodimerization. Polym. J. 2020, 52, 1027-1034. [CrossRef]

7. Chang, V.Y.; Fedele, C.; Priimagi, A.; Shishido, A.; Barrett, C.J. Photoreversible Soft Azo Dye Materials: Toward Optical Control of Bio-Interfaces. Adv. Opt. Mater. 2019, 7, 1900091. [CrossRef]

8. Matczyszyn, K.; Sworakowski, J. Phase change in azobenzene derivative-doped liquid crystal controlled by the photochromic reaction of the dye. J. Phys. Chem. B 2003, 107, 6039-6045. [CrossRef]

9. De Haan, L.T.; Schenning, A.P.H.J.; Broer, D.J. Programmed morphing of liquid crystal networks. Polymer 2014, 55, 5885-5896. [CrossRef]

10. Stoychev, G.; Kirillova, A.; Ionov, L. Light-Responsive Shape-Changing Polymers. Adv. Opt. Mater. 2019, 7, 1900067. [CrossRef]

11. Serak, S.; Tabiryan, N.; Vergara, R.; White, T.J.; Vaia, R.A.; Bunning, T.J. Liquid crystalline polymer cantilever oscillators fueled by light. Soft Matter 2010, 6, 779-783. [CrossRef]

12. Ma, S.; Li, X.; Huang, S.; Hu, J.; Yu, H. A Light-Activated Polymer Composite Enables On-Demand Photocontrolled Motion: Transportation at the Liquid/Air Interface. Angew. Chem. 2019, 131, 2681-2685. [CrossRef]

13. Sung, H.; Kim, H.; Choi, J.; Kim, H.; Li, C.; Cho, M. Structural design of soft robotics using a joint structure of photoresponsive polymers. Smart Mater. Struct. 2020, 29, 055032. [CrossRef] 
14. Da Cunha, M.P.; Debije, M.G.; Schenning, A.P.H.J. Bioinspired light-driven soft robots based on liquid crystal polymers. Chem. Soc. Rev. 2020, 49, 6568-6578. [CrossRef] [PubMed]

15. Shen, Z.; Chen, F.; Zhu, X.; Yong, K.T.; Gu, G. Stimuli-responsive functional materials for soft robotics. J. Mater. Chem. B 2020, 8 , 8972-8991. [CrossRef] [PubMed]

16. Rippa, M.; Castagna, R.; Marino, A.; Tkachenko, V.; Palermo, G.; Pane, A.; Umeton, C.; Tabiryan, N.; Petti, L. Thue-Morse nanostructures for tunable light extraction in the visible region. Opt. Lasers Eng. 2018, 104, 291-299. [CrossRef]

17. Caligiuri, V.; De Sio, L.; Petti, L.; Capasso, R.; Rippa, M.; Maglione, M.G.; Tabiryan, N.; Umeton, C. Electro/All Optical Light Extraction in Gold Photonic Quasi-Crystals Layered with Photosensitive Liquid Crystals. Adv. Opt. Mater. 2014, 2, 950-955. [CrossRef]

18. Ishihara, S.; Wakemoto, H.; Nakazima, K.; Matsuo, Y. The effect of rubbed polymer films on the liquid crystal alignment. Liq. Cryst. 1989, 4, 669-675. [CrossRef]

19. Broer, D.J.; Boven, J.; Mol, G.N. In-situ photopolymerization of oriented liquid-crystalline acrylates, 3. Oriented polymer networks from a mesogenic diacrylate. Makromol. Chem. 1989, 190, 2255-2268. [CrossRef]

20. Hrozhyk, U.A.; Serak, S.V.; Tabiryan, N.V.; White, T.J.; Bunning, T.J. Optically switchable, rapidly relaxing cholesteric liquid crystal reflectors. Opt. Express 2010, 18, 9651. [CrossRef] [PubMed]

21. Ube, T.; Ikeda, T. Cross-linked liquid-crystalline polymers as photomobile materials. Mech. Responsive Mater. Soft Robot. 2019, 8, 209-232. [CrossRef]

22. Koshima, H. Mechanically Responsive Materials for Soft Robotics; Wiley: Hoboken, NJ, USA, 2020; ISBN 9783527346202.

23. Wu, Y.; Zhang, Q.; Kanazawa, A.; Shiono, T.; Ikeda, T.; Nagase, Y. Photoinduced alignment of polymer liquid crystals containing azobenzene moieties in the side chain. 5. Effect of the azo contents on alignment behavior and enhanced response. Macromolecules 1999, 32, 3951-3956. [CrossRef]

24. Yu, Y.; Nakano, M.; Shishido, A.; Shiono, T.; Ikeda, T. Effect of Cross-linking Density on Photoinduced Bending Behavior of Oriented Liquid-Crystalline Network Films Containing Azobenzene. Chem. Mater. 2004, 16, 1637-1643. [CrossRef]

25. De Haan, L.T.; Sánchez-Somolinos, C.; Bastiaansen, C.M.W.; Schenning, A.P.H.J.; Broer, D.J. Engineering of Complex Order and the Macroscopic Deformation of Liquid Crystal Polymer Networks. Angew. Chemie 2012, 124, 12637-12640. [CrossRef]

26. Yu, Y.; Nakano, M.; Ikeda, T. Directed bending of a polymer film by light. Nature 2003, 425, 145. [CrossRef] [PubMed]

27. White, T.J.; Serak, S.V.; Tabiryan, N.V.; Vaia, R.A.; Bunning, T.J. Polarization-controlled, photodriven bending in monodomain liquid crystal elastomer cantilevers. J. Mater. Chem. 2009, 19, 1080-1085. [CrossRef]

28. Zeng, H.; Lahikainen, M.; Liu, L.; Ahmed, Z.; Wani, O.M.; Wang, M.; Yang, H.; Priimagi, A. Light-fuelled freestyle self-oscillators. Nat. Commun. 2019, 10, 5057. [CrossRef] [PubMed]

29. Lahikainen, M.; Zeng, H.; Priimagi, A. Reconfigurable photoactuator through synergistic use of photochemical and photothermal effects. Nat. Commun. 2018, 9, 4148. [CrossRef]

30. Kondo, M.; Sugimoto, M.; Yamada, M.; Naka, Y.; Mamiya, J.I.; Kinoshita, M.; Shishido, A.; Yu, Y.; Ikeda, T. Effect of concentration of photoactive chromophores on photomechanical properties of crosslinked azobenzene liquid-crystalline polymers. J. Mater. Chem. 2010, 20, 117-122. [CrossRef]

31. Bukowczan, A.; Hebda, E.; Pielichowski, K. The influence of nanoparticles on phase formation and stability of liquid crystals and liquid crystalline polymers. J. Mol. Liq. 2021, 321, 114849. [CrossRef]

32. Gdovinová, V.; Schroer, M.A.; Tomašovičová, N.; Appel, I.; Behrens, S.; Majorošová, J.; Kováč, J.; Svergun, D.I.; Kopčanský, P. Structuralization of magnetic nanoparticles in 5CB liquid crystals. Soft Matter 2017, 13, 7890-7896. [CrossRef] [PubMed]

33. Sikharulidze, D. Nanoparticles: An approach to controlling an electro-optical behavior of nematic liquid crystals. Appl. Phys. Lett. 2005, 86, 033507. [CrossRef]

34. Shen, Y.; Dierking, I. Perspectives in liquid-crystal-aided nanotechnology and nanoscience. Appl. Sci. 2019, 9, 2512. [CrossRef]

35. Lu, X.; Zhang, H.; Fei, G.; Yu, B.; Tong, X.; Xia, H.; Zhao, Y. Liquid-Crystalline Dynamic Networks Doped with Gold Nanorods Showing Enhanced Photocontrol of Actuation. Adv. Mater. 2018, 30, 1706597. [CrossRef]

36. Kohlmeyer, R.R.; Chen, J. Wavelength-Selective, IR Light-Driven Hinges Based on Liquid Crystalline Elastomer Composites. Angew. Chem. 2013, 125, 9404-9407. [CrossRef]

37. Kumar, S.; Sahare, P.D. Observation of band gap and surface defects of $\mathrm{ZnO}$ nanoparticles synthesized via hydrothermal route at different reaction temperature. Opt. Commun. 2012, 285, 5210-5216. [CrossRef]

38. Jangir, L.K.; Kumari, Y.; Kumar, A.; Kumar, M.; Awasthi, K. Investigation of luminescence and structural properties of ZnO nanoparticles, synthesized with different precursors. Mater. Chem. Front. 2017, 1, 1413-1421. [CrossRef]

39. Khan, A.; Ali, H.M.; Nazir, R.; Ali, R.; Munir, A.; Ahmad, B.; Ahmad, Z. Experimental investigation of enhanced heat transfer of a car radiator using $\mathrm{ZnO}$ nanoparticles in $\mathrm{H}_{2} \mathrm{O}$-ethylene glycol mixture. J. Therm. Anal. Calorim. 2019, 138, 3007-3021. [CrossRef]

40. Li, S.; Silvers, S.J.; El-Shall, M.S. Preparation, characterization and optical properties of zinc oxide nanoparticles. Mater. Res. Soc. Symp.-Proc. 1997, 452, 389-394. [CrossRef]

41. Mishra, P.K.; Mishra, H.; Ekielski, A.; Talegaonkar, S.; Vaidya, B. Zinc oxide nanoparticles: A promising nanomaterial for biomedical applications. Drug Discov. Today 2017, 22, 1825-1834. [CrossRef] [PubMed]

42. Suntako, R. Effect of synthesized $\mathrm{ZnO}$ nanoparticles on thermal conductivity and mechanical properties of natural rubber. IOP Conf. Ser. Mater. Sci. Eng. 2018, 284, 012017. [CrossRef] 
43. Topnani, N.; Hamplová, V.; Kašpar, M.; Novotná, V.; Gorecka, E. Synthesis, characterisation and functionalisation of ZnO and $\mathrm{TiO}_{2}$ nanostructures: Used as dopants in liquid crystal polymers. Liq. Cryst. 2014, 41, 91-100. [CrossRef]

44. Qi, H.; Kinkead, B.; Marx, V.M.; Zhang, H.R.; Hegmann, T. Miscibility and alignment effects of mixed monolayer cyanobiphenyl liquid-crystal-capped gold nanoparticles in nematic cyanobiphenyl liquid crystal hosts. ChemPhysChem 2009, 10, 1211-1218. [CrossRef] [PubMed]

45. Khatua, S.; Manna, P.; Chang, W.; Tcherniak, A.; Friedlander, E.; Zubarev, E.R.; Link, S. Plasmonic Nanoparticles-Liquid Crystal Composites. J. Phys. Chem. C 2010, 114, 7251-7257. [CrossRef]

46. Kanie, K.; Muramatsu, A. Organic-inorganic hybrid liquid crystals: Thermotropic mesophases formed by hybridization of liquid-crystalline phosphates and monodispersed $\alpha-\mathrm{Fe}_{2} \mathrm{O}_{3}$ particles. J. Am. Chem. Soc. 2005, 127, 11578-11579. [CrossRef] [PubMed]

47. Saliba, S.; Mingotaud, C.; Kahn, M.L.; Marty, J.D. Liquid crystalline thermotropic and lyotropic nanohybrids. Nanoscale 2013, 5, 6641-6661. [CrossRef] [PubMed]

48. Shah, S.M.; Martini, C.; Ackermann, J.; Fages, F. Photoswitching in azobenzene self-assembled monolayers capped on zinc oxide: Nanodots vs. nanorods. J. Colloid Interface Sci. 2012, 367, 109-114. [CrossRef]

49. Khayyami, A.; Karppinen, M. Reversible Photoswitching Function in Atomic/Molecular-Layer-Deposited ZnO:Azobenzene Superlattice Thin Films. Chem. Mater. 2018, 30, 5904-5911. [CrossRef]

50. Xu, J.; Sagnelli, D.; Faisal, M.; Perzon, A.; Taresco, V.; Mais, M.; Giosafatto, C.V.L.; Hebelstrup, K.H.; Ulvskov, P.; Jørgensen, B.; et al. Amylose/cellulose nanofiber composites for all-natural, fully biodegradable and flexible bioplastics. Carbohydr. Polym. 2021, 253, 117277. [CrossRef]

51. Dong, L.; Chen, Y.; Zhai, F.; Tang, L.; Gao, W.; Tang, J.; Feng, Y.; Feng, W. Azobenzene-based solar thermal energy storage enhanced by gold nanoparticles for rapid, optically-triggered heat release at room temperature. J. Mater. Chem. A 2020, 8 , 18668-18676. [CrossRef]

52. Sagnelli, D.; Cavanagh, R.; Xu, J.; Swainson, S.M.E.; Blennow, A.; Duncan, J.; Taresco, V.; Howdle, S. Starch/Poly (GlycerolAdipate) Nanocomposite Film as Novel Biocompatible Materials. Coatings 2019, 9, 482. [CrossRef]

53. Sagnelli, D.; Vestri, A.; Curia, S.; Taresco, V.; Santagata, G.; Johansson, M.K.G.; Howdle, S.M. Green enzymatic synthesis and processing of poly (cis-9,10-epoxy-18-hydroxyoctadecanoic acid) in supercritical carbon dioxide $\left(\mathrm{scCO}_{2}\right)$. Eur. Polym. J. 2021, 161, 110827. [CrossRef]

54. Latha, D.M.; Pisipati, V.G.K.M.; Pardhasaradhi, P.; Datta Prasad, P.V.; Rao, D.V. Estimation of order parameter from different models in symmetric dimeric liquid crystals. Liq. Cryst. Today 2014, 23, 54-60. [CrossRef]

55. Wang, H.; Hor, J.L.; Zhang, Y.; Liu, T.; Lee, D.; Fakhraai, Z. Dramatic Increase in Polymer Glass Transition Temperature under Extreme Nanoconfinement in Weakly Interacting Nanoparticle Films. ACS Nano 2018, 12, 5580-5587. [CrossRef] [PubMed]

56. Nenna, G.; De Girolamo Del Mauro, A.; Massera, E.; Bruno, A.; Fasolino, T.; Minarini, C. Optical properties of polystyrene-ZnO nanocomposite scattering layer to improve light extraction in organic light-emitting diode. J. Nanomater. 2012, 2012, 5. [CrossRef] 